\title{
Jurisdicción municipal y poder eclesiástico en la Zamora medieval ${ }^{1}$
}

\author{
Florián Ferrero Ferrero *
}

\section{JURISDICCIÓN CONCEJIL}

Cabe pensar que los territorios que fueron configurando la "tierra" zamorana siguieron un proceso de repoblación paralelo a los esfuerzos de restaurar la ciudad en tiempos de Alfonso III y, fundamentalmente, de Fernando I, tal como ya ha señalado Manuel Fernando Ladero ${ }^{2}$.

Desde el reinado de Fernando I se observa un proceso planificado de repoblación y, al mismo tiempo, de formación de la jurisdicción de Zamora, principalmente, con los trabajos emprendidos por Raimundo de Borgoña.

Son muchos los ejemplos de concesión de fueros a tierras zamoranas en el siglo XI y principios del XII; siendo los ejemplos más conocidos los de Santa Cristina y El Valle.

El primero de ellos fue otorgado por Fernando I, en 1062, poco tiempo después de la carta foral a Zamora, a la que hace referencia ${ }^{3}$.

Las primeras referencias a territorios más alejados de la ciudad ${ }^{4}$ son los fueros de Salmas y El Valle.

* Archivo Histórico Provincial de Zamora.

' Ponencia desarrollada en las Jornadas "893-1993. Zamora, 1.100 años de historia", celebradas en Zamora del 13 al 16 de octubre de 1993.

2 M. F. Ladero Quesada: La ciudad de Zamora en la época de los Reyes Católicos. Economía $y$ gobierno. Instituto de Estudios Zamoranos, Zamora, 1991; p. 10.

3 ACZa., Legajo 8, ํㅡ 2.

- Santa Cristina estaba situada a escasa distancia de la ciudad, en la confluencia de los rios Duero y Valderaduey. 
Ambos lugares fueron repoblados por Raimundo de Borgoña, y se encontraban situados no lejos de la actual población de Bamba.

Del fuero de Salmas, concedido presumiblemente en la década de 1090 , sólo conocemos la referencia que nos proporciona el de El Valle, sobre los homicidios, rauso, mañeria, fonsado y fonsadera ${ }^{5}$.

En 1094, Raimundo de Borgoña, junto con su esposa la infanta Urraca Alfónsiz, confirma los fueros del lugar de El Valle ${ }^{6}$.

Aunque normalmente este lugar se ha identificado con los actuales Barrios Bajos zamoranos, que también reciben este nombre, nosotros nos inclinamos por situarlos en las proximidades de Bamba, donde tuvieron su asentamiento Santa María del Valle y San Miguel del Valle, como ya apuntó en su momento Marciano Sánchez ${ }^{7}$.

En el siglo XII se va a contemplar el otorgamiento de fueros y fueroscontratos agrarios a un gran número de lugares de las Tierras del Pan, del Vino y de Sayago; en su mayor parte concedidos por la iglesia ${ }^{8}$.

Coincidente con esta actividad repobladora y normativa, se va a ir haciendo cada vez más patente en la documentación el término "tierra de Zamora" para denotar la dependencia jurisdiccional al concejo de la ciudad.

Muchas serían las citas que podríamos aducir, pero basten algunos ejemplos para confirmarlo.

Así, en 1150, María Aldemíriz, su segundo esposo, los hijos de su primer matrimonio y Pedro Salvadórez, venden a Andrés Ordóñez y a su mujer María Vidas una heredad en Bamba, en territorio de Zamora - «et habeat iacentia in territorio zamorense, in villa qua vocitant Bamba»-; y se señala, además, que el territorio fue repoblado por Raimundo de

\footnotetext{
5 ACZa., Legajo 10bis, $n^{\circ} 1$ (TNZa.), ff. CXXIv-CXXIIr; $n^{\circ} 2$ (TBZa.), f. $61 \mathrm{v}$.

"... in primis quales habuerunt in Salmas, non corra inter vos homicidio, nec rosso, nec maneria, nec uadatis in fossato, nec detis in fossadera...".

"... illa serna sedeat in Salmas...".

lbidem.

M. SANCHEZ Rodriguez: Fueros y posturas de Zamora (Tumbos Blanco y Negro). Salamanca, 1987 , pp. 3-5.

J. Rodriguez Fernandez: Los Fueros locales de la provincia de Zamora. Junta de Castilla y León, 1990, pp. 43-44.

F. Ferrero FERrero: "Fuero de El Valle", Civitas, MC aniversario de la ciudad de Zamora. Zamora, 1993, p. 239.

Entre otras razones bastaria con la de figurar el lugar entre los del cillero de Santa María del Valle.

8 M. SAnChez RodRíguez: Fueros y posturas...

J. Rodriguez Fernandez: Opus cit.
} 
Borgoña: “... quod pertinet ad Bamba sicut comes Raimundus populavit eam .... ${ }^{9}$.

En 1176, en la donación de Fernando II del lugar de Avedillo al obispo $y$ al cabildo se señala que «Doy y concedo ... en término de Zamora aqueIla villa llamada Avedillo» ${ }^{10}$.

También hay una repoblación del territorio de origen señorial laico. Así conocemos que Villamor de los Escuderos «pobróla don Pelay Vilidez e sua muyer Mayor Échez e dioya el emperador en donatión e fue pobrada a fuero de Xema, de que era término" "1.

Como ha señalado M. F. Ladero ${ }^{12}$, a comienzos del siglo XIII parece que la jurisdicción zamorana está ya delimitada y así lo pone de manifiesto la documentación referida a Fermoselle, a Gema, a Villalcampo o a la zona de Venialbo ${ }^{13}$.

Como él mismo señala ${ }^{14}$, el documento que parece indicar que el proceso de conformación y delimitación de la jurisdicción municipal zamorana ha concluido es el de Alfonso IX, de 1229, por el que confirma al obispo, cabildo y a todos los clérigos del obispado de Zamora la posesión de los bienes de realengo ganados hasta ese momento y les prohibe que, en lo sucesivo, adquieran más o de "iunioribus regalengis" sin autorización real; pero les permite obtener los de los nobles, hidalgos, hombres de behetría, clérigos y órdenes así como bienes de realengo de los ciudadanos y burgueses que no les hubieran sido dados "ad populationem uel ad forum» 15.

Es decir, estamos ante el reconocimiento real de la situación de la jurisdicción de la iglesia de Zamora hasta ese momento, pero también ante su deseo de fortalecer y preservar la realenga.

Se consolida así una jurisdicción zamorana integrada por las comarcas naturales del Pan, del Vino y de Sayago, en las que aparecen enclaves jurisdiccionales eclesiásticos - tanto del obispo, como del cabildo, como de monasterios- y tierras señoriales laicas.

\footnotetext{
9 ACZa., Legajo 16, 2. ${ }^{\text {a }}$ parte, $n^{0} 19$.

10 ACZa., Legajo 8, $n^{\circ} 30$.

"Do et concedo... in termino Camore illam villam dictam Viadellum".

" M. SÁnChez RodRíguez: Fueros y posturas..., pp. 98-99.

J. Rodriguez Fernández: Opus cit., p. 285.

ACZa., Legajo 10 bis, $n^{\circ} 2$ (TBZa.), f. $148 \mathrm{v}$.

12 M. F. Ladero Quesada: Opus cit., pp. 10-11.

13 ACZa., Legajos 13, no 33; 14, no 29; 15, n $3,4,7$ y 15; y $17, n^{\circ} 1$ y 22.

14 M. F. Ladero Quesada: Opus cit., p. 11.

is ACZa., Legajos 2, no 78a; y 10bis, $n^{\circ} 1$ (TNZa.), f. Lllr-v.
} 
En el siglo XV dicha jurisdicción se irá estructurando en Partidos, que tomarán los nombres ya varias veces citados de Tierra del Pan, Tierra del Vino y Sayago, que rodean a la ciudad.

Veamos cada uno de ellos.

\section{a) Zamora:}

La primera delimitación que conocemos de la ciudad de Zamora nos la ofrece el Fuero otorgado por Alfonso IX, el año 1208, en cuyo parágrafo 19 se señala que: "E estos homezianes ayan atal couto por el monte d'Aloa, por el Camín de Johán Cidiélez, e por Morales, e por Ponteyos de la Torre, e por Arcinielas, e por Vilaralvo el Mayor, e por Cubiellos, e por Sancta María de la Iniesta, e por las Manbras, e por los penedos de Congosta, e por Carrascal, que dizen Aldea de Pelay Alvo" ${ }^{16}$.

Territorio que no se aparta demasiado del actual, excepción hecha del lado occidental, ya que, por estar aún pobladas, eran aldeas y lugares la mayor parte de las actuales dehesas; y que se va a mantener, como más tarde veremos hasta, al menos, el siglo XVI ${ }^{17}$.

Dentro de este espacio, junto con el núcleo urbano propiamente dicho, rodeado de murallas, irán apareciendo diversos arrabales, siendo los principales los de ${ }^{18}$ :

La puebla de la Puente

La puebla de Sante Frontes

La puebla de Santi Espiritus

\section{Olivares}

Arrabales, que según los repartimientos de 1484 tenian $10,50,5$ y 10 vecinos pecheros respectivamente ${ }^{19}$.

${ }_{16}$ BNM., ms. 6502 (Fuero de Zamora), no 19.

J. MAJADA NEILA: Fuero de Zamora. Introducción, transcripción, vocabulario. Libreria Cervantes, Salamanca, 1983.

Se corresponden con las poblaciones de Morales del Vino, Pontejos, Arcenillas, Villaralbo, Cubillos, La Hiniesta y Carrascal; y con el despoblado de Congosta.

Desconocemos la situación del monte de Aloa, del Camín de Johán Cidélez -que podría tratarse de uno de los actuales Alcamines- y de las Mambras.

17 En este sentido son muy esclarecedores los diversos repartimientos de fines del siglo XV.

18 Actuales barrios de Cabañales, San Frontis, Espíritu Santo y Olivares.

19 AHPZa.: Sección Municipal: Zamora, Legajo B-1 <provisional>. "Repartimiento de los peones y bestias", de 1484 . 
Sin que se pueda señalar claramente si pertenecen a la ciudad o a la Tierra del Vino, aunque nos inclinamos por lo primero, se citan siguientes lugares, todos ellos al sur del Duero:

Carpentero, Valpalacio, Las Chanas, Pinilla, La Corneja, El Sepulcro y la Granja de Valparaíso.

\section{b) Tierra del Pan:}

Se trata de la única tierra perteneciente al concejo zamorano situada al norte del río Duero, que es junto con el Esla, que le sirve de cierre por el oeste, los dos accidentes geográficos claros en su delimitación.

Más imprecisas son sus "rayas» del este y del norte. La primera de ambas es la Tierra de Toro, objeto - como en su momento veremos- de menos conflictos de los que cabía suponer. La segunda se debate entre lugares pertenecientes al monasterio de Moreruela o a la Orden de Santiago.

Los diversos repartimientos realizados a fines del siglo XV por el concejo zamorano nos permiten fijar en la actualidad, sin ningún tipo de problema esta tierra zamorana en dicho período ${ }^{20}$.

Así podemos señalar como pertenecientes a esta tierra los siguientes lugares dependientes del concejo de Zamora ${ }^{21}$ :

$\begin{array}{ll}\text { Aldea Rodrígo y Los Pisones }^{22} & \text { Algodre } \\ \text { Almarás }^{23} & \text { Andavias } \\ \text { Aspariegos }^{25} & \text { Benexiles }^{24} \\ \text { Casasola }^{25} & \text { Çerezinos }^{26}\end{array}$

20 Los repartimientos principales que hemos utilizado son los del "salario del corregidor", "salarios de los alcaldes de fuero y al pesquisidor", "para los peones y bestias", de los años 1483-1500.

AHPZa.: Sección Municipal: Zamora, Legajo B- <provisionals.

Sobre dichos repartimientos trabaja en la actualidad V. A. CARBA.JO MARTiN, a quien agradecemos los datos que nos ha proporcionado.

${ }_{21}$ Cuando el nombre del lugar coincide con la actual población no señalamos nada.

22 Actualmente dehesa denominada Aldea y pago de Los Pisones, en término de Zamora, aguas abajo del Duero, limitando con La Hiniesta al norte y la dehesa de San Julián al oeste.

23 Actualmente Almaraz de Duero.

${ }_{24}$ Actualmente Benegiles.

25 En la actualidad es un despoblado junto a Monfarracinos.

${ }^{26}$ Actual Cerecinos del Carrizal. 


\begin{tabular}{|c|c|}
\hline Cobillos $^{27}$ & Cureses $^{28}$ \\
\hline Espariegos $^{29}$ & Gallegos ${ }^{30}$ \\
\hline Lenguar ${ }^{31}$ & Molazillos ${ }^{32}$ \\
\hline Monfarracinos & Montamarta \\
\hline Monzón ${ }^{33}$ & Moreruela ${ }^{34}$ \\
\hline Muelas ${ }^{35}$ & Palacios ${ }^{36}$ \\
\hline Palomares ${ }^{37}$ & Pobladura ${ }^{38}$ \\
\hline Roales ${ }^{39}$ y Villanueva ${ }^{40}$ & San Pelayo ${ }^{41}$ \\
\hline Santa Christina ${ }^{42}$ & Santandrés 43 \\
\hline Torres ${ }^{44}$ & Valcabado \\
\hline Valverde ${ }^{45}$ & Venexiles ${ }^{46}$ \\
\hline Villagodio 47 & Villalube \\
\hline Villarseco 48 & La Yniesta ${ }^{49}$ \\
\hline
\end{tabular}

También suelen citarse como lugares de la Tierra del Pan los arrabales zamoranos de Olivares y Espiritu Santo.

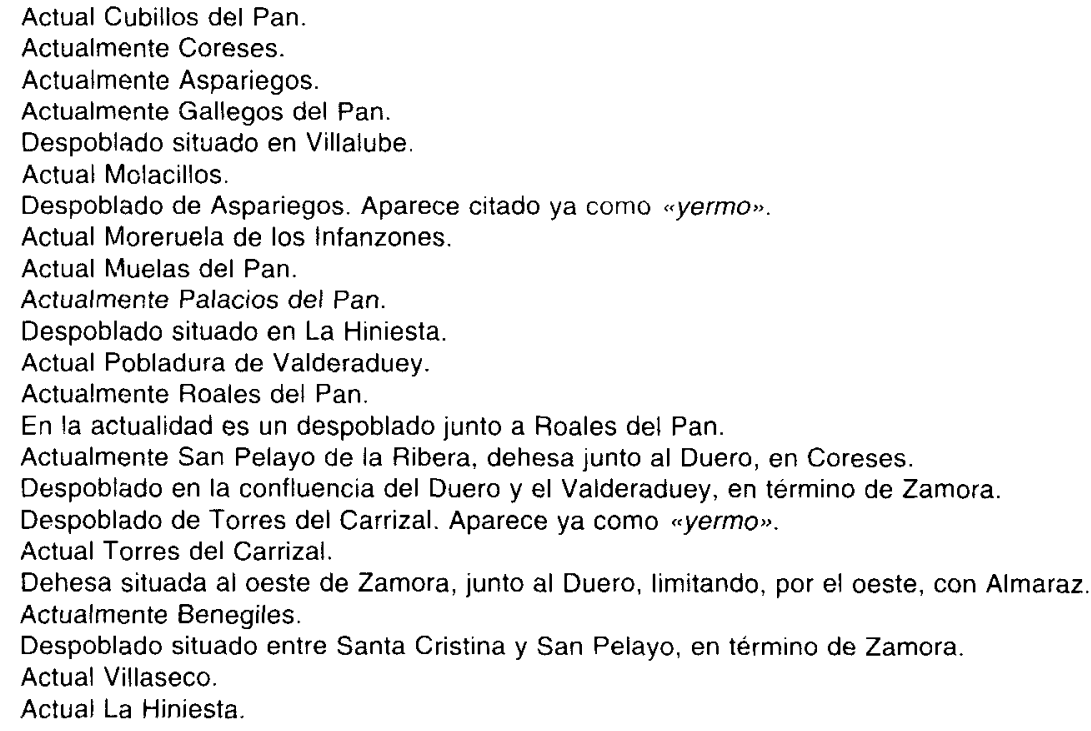


Asimismo, aunque no aparezcan en ninguno de los repartimientos de fines del siglo $\mathrm{XV}$, en diversos momentos de dicha centuria pueden constatarse como lugares de la Tierra del Pan los de Valcabadino, Penadillo, Merendeses, Gijón y Valdelaloba ${ }^{50}$; así como los de Valduercos y Toral ${ }^{51}$.

Según el repartimiento de "peones y bestias" de 1484, vivían en dicha Tierra del Pan un conjunto de 897 vecinos pecheros; siendo las poblaciones más importantes las de Montamarta y Cubillos con 100 vecinos cada una, seguidas de Muelas con 82, de Villalube con 70 y Coreses con 60; y las menores las de Palomares con uno, Valverde con dos, Aldea Rodrigo y los Pisones con un total de cuatro, y Pobladura y Villagodio con seis cada una.

\section{c) Tierra del Vino:}

Situada al sudeste de la ciudad de Zamora, es la Tierra que presenta más dificultades de delimitación, dado que, salvo por el norte en el que el Duero es su límite natural, no existen accidentes geográficos claros que la definan. Por ello, y por partir "raya» por ella el alfoz de Toro fue fuente de numerosos conflictos.

Abundan en su zona además varios enclaves dependientes de la iglesia y de señoríos laicos.

Por los diversos repartimientos de fines del siglo XV, en los que aparece unida a los arrabales de Zamora y sin que nunca figure el nombre de Tierra del Vino, podemos determinar que en esos momentos estaba constituida por los siguientes lugares y aldeas dependientes jurisdiccionalmente del concejo zamorano ${ }^{52}$ :

so M. F. Ladero Quesada: Opus cit., pp. 13-14.

Señala la existencia de estos lugares así como el de Las Chanicas, que nosotros creemos deberia incluirse en la Tierra de Sayago.

Todos está situados en las proximidades de Zamora.

5) Valduercos también es denominado San Pedro de Balduercos. Se situaban a escasa distancia de La Hiniesta.

J. MARTINEz de VEGA: “Discurso 6: Historial de la ymvención y algunos milagros de Nuestra Señora de la Yniesta". AHDZa.: Parroquiales: San Pedro y San lldefonso de Zamora (281-14), $\mathrm{n}^{2} 96$, p. 73 .

Cfr. F. Ferrero Ferrero: VII siglos de Romeria a La Hiniesta. Documentos. Archivo Histórico Provincial de Zamora, Zamora, 1991, p. 55

52 Los repartimientos principales que hemos utilizado son los del "salario del corregidor", "salarios de los alcaldes de fuero y al pesquisidor", "para los peones y bestias", de los años 1483-1500.

AHPZa.: Sección Municipal: Zamora, Legajo B-1 <provisional>. 
Ei Aldea del Palo ${ }^{53}$

El Almancaya ${ }^{55}$

Arguxillo ${ }^{56}$

Los Barrios ${ }^{58}$

Casaseca de Campeán

Casasola ${ }^{60}$

El Corralino ${ }^{61}$

El Espital ${ }^{63}$

La Laguna ${ }^{65}$

La Mañana ${ }^{66}$

Moraleja ${ }^{68}$

Oter de Obispo ${ }^{70}$

Peleas de Yuso ${ }^{72}$

Pontejos

San Pedro el Royo ${ }^{74}$
Aldeanueva de las Chanas ${ }^{54}$

Arcenillas

Aribayos ${ }^{57}$

Caçurra ${ }^{59}$

Casaseca de las Chanas

Corrales

Entrala y La Torre ${ }^{62}$

La Fuente del Carnero ${ }^{64}$

Madridanos

Mermillo de Campeán ${ }^{67}$

Morales ${ }^{69}$

Peleas de Suso ${ }^{71}$

El Perdigón

San Miguell de Bobadilla ${ }^{73}$

Sant Marçal ${ }^{75}$ y Santistevan ${ }^{76}$

53 Actualmente San Miguel de la Ribera.

54 Despoblado de Casaseca de Campeán.

55. Actualmente un despoblado en Gema.

56 Actualmente Argujillo.

57 Existían dos despoblados con este nombre - Aribayos de Arriba y Aribayos de Abajo- en las proximidades de Bamba.

58 Posible despoblado de Casaseca de Campeán.

sa Actual Cazurra.

60 Posible despoblado de Casaseca de Campeán.

61 Despoblado de Corrales.

62 Forma una unidad con la actual Entrala. Antes se llamaba La Torre del Salinar.

69 Despoblado con el nombre de El Hospital en Villanueva de Campeán.

64 Actualmente Fuentelcarnero.

65 Actual despoblado en Casaseca de Campeán.

6E Despoblado junto a Peleas de Abajo.

67 Posible despoblado junto a El Perdigón.

68 Actual Moraleja del Vino.

69 Actual Morales del Vino.

- Actualmente Tardobispo.

Actualmente Peleas de Arriba.

Actualmente Peleas de Abajo.

Actual despoblado de San Miguel de Bobadilla, en Zamora, lindando al este con Villaralbo.

74 Posible despoblado de Casaseca de Campeán.

75 Actualmente San Marcial.

${ }_{76}$ Es San Esteban, despoblado de San Marcial. 
Sant Pedro de Campeán ${ }^{77}$

Tardaguila ${ }^{79}$

Villagrán ${ }^{81}$

Villanueva de Valdexema ${ }^{82}$

Villaralbino ${ }^{84}$
Santa Marina de Troncas ${ }^{78}$

EI Vayllo ${ }^{80}$

Villanueva de Campeán

Villañazá ${ }^{83}$

Villaralbo

d) Tierra de Sayago:

Perfectamente delimitado su territorio en sus lados norte y oeste por el río Duero, también lo es en gran medida por el sur mediante el Tormes. El este será la zona menos delimitada, hasta el punto de que, como ha indicado M. F. Ladero Quesada, se intenta señalar en las Ordenanzas de la Tierra ${ }^{85}$.

Está salpicada de diferentes lugares bajo dependencia de la iglesia.

Por los repartimientos de fines del siglo XV, se puede conocer que los lugares dependientes del concejo zamorano eran los siguientes en la segunda mitad de esa centuria ${ }^{86}$ :

Los Alcamines ${ }^{87}$

Algamín $^{89}$
Alfarás ${ }^{88}$

Algosino ${ }^{90}$

7 Actual despoblado en Casaseca de Campeán.

78 Despoblado de Villanueva de Campeán.

79 Posible despoblado de Casaseca de Campeán.

${ }_{80}$ Despoblado con el nombre de Baillo junto a El Perdigón.

${ }^{81}$ Despoblado de Villanueva de Campeán.

82 Actual despoblado de Villanueva de Valdegema, en Villalazán.

83 Actual Villalazán.

64 Despoblado de Villaralbo.

as M. F. Ladero Quesada: Opus cit., p. 16.

C. del Canto de la Fuente, V. A. Carbajo Martin, S. Moreta Velayos: Ordenanzas Municipales de Zamora. Siglos XV y XVI. Diputación de Zamora, Zamora, 1991.

AHPZa:: Sección Municipal: Zamora, Legajo XV, n 1-22 y 27.

${ }^{86}$ Los repartimientos principales que hemos utilizado son los del "Salario del corregidor", "salarios de los alcaldes de fuero y al pesquisidor", "para los peones y bestias", de los años 1483-1500.

AHPZa:: Sección Municipal: Zamora, Legajo B-1 <provisional>.

87 Se trata de los despoblados de Alcamín Alto y Alcamin Bajo, en Tardobispo.

88 Actualmente Alfaraz.

89 Actualmente Argañín.

90 Actualmente Argusino, desaparecido hace escasos años bajo las aguas del embalse de Almendra. 


\begin{tabular}{|c|c|}
\hline Almeyda ${ }^{91}$ & Avelón ${ }^{92}$ \\
\hline Bovadilla ${ }^{93}$ & Cabañas ${ }^{94}$ \\
\hline Çafara ${ }^{95}$ & Calvellino ${ }^{96}$ \\
\hline Carrascal & Corporales $^{97}$ \\
\hline Coscorrita 98 & Escuadro \\
\hline Fadón & Fariza \\
\hline Figueruela 99 & Fontanillas ${ }^{100}$ \\
\hline Formarís ${ }^{101}$ & Fresnadillo \\
\hline Fresno de Çamora ${ }^{102}$ & Furnias ${ }^{103}$ \\
\hline Gamones con la Torre ${ }^{104}$ & Gáname \\
\hline El Huelmo ${ }^{105}$ & Las Inillas ${ }^{106}$ \\
\hline Llamas de Suso ${ }^{107}$ y Sesmir ${ }^{108}$ & Llamas de Yuso ${ }^{109}$ y Amor ${ }^{110}$ \\
\hline Malillos & Mermillo de Sayago ${ }^{111}$ \\
\hline Monumenta & Moral \\
\hline Moralina & La Muga ${ }^{112}$ \\
\hline Mugátar ${ }^{113}$ y Los Maniles ${ }^{114}$ & Palaçuelo con Mámules ${ }^{115}$ \\
\hline
\end{tabular}

9. Actual Almeida de Sayago.

92 Actualmente Abelón.

93 Actual Badilla.

${ }^{94}$ Actual Cabañas de Sayago.

95 Actualmente Zafara.

96 Actualmente Carbellino.

97 Actualmente es una dehesa en Bermillo de Sayago.

98 Actualmente Cozcurrita.

99 Actualmente Figueruela de Sayago.

100 Dehesa en Arcillo.

101 Actualmente Formariz.

102 Actualmente Fresno de Sayago. También denominado Fresno del Barrio.

103 Despoblado de Carrascal.

104 Actuales Gamones y Torregamones.

105 Actualmente Luelmo.

108 Actualmente Las Enillas.

107 Actual Llamas de Arriba, despoblado en Cabañas de Sayago.

${ }_{108}$ Actualmente Sesmil, despoblado en Cabañas de Sayago.

109 Actualmente Llamas de Abajo, despoblado en el término de Cabañas de Sayago.

"Despoblado en La Tuda.

111 Actualmente Bermillo de Sayago.

112 Actualmente Muga de Sayago.

113 Actualmente Mogátar.

114 Barrio de Mogatar.

115 Actuales Palazuelo y Mámoles. 


\begin{tabular}{|c|c|}
\hline Pasariegos & Pelaças ${ }^{116}$ \\
\hline Pereruela & Pinolino ${ }^{117}$ \\
\hline Pinuel ${ }^{118}$ & Ruelos ${ }^{119}$ \\
\hline Salse ${ }^{120}$ & La Sernazina ${ }^{121}$ \\
\hline Sobradillo de Formarís ${ }^{122}$ & Sobradillo de Palomares \\
\hline Sogo & Tamame \\
\hline Torre de Frades ${ }^{123}$ & Tudera \\
\hline La Vega ${ }^{124}$ y Veguellina ${ }^{125}$ & Villadepera \\
\hline Villamor de Cadoços ${ }^{126}$ & Villamor de la Ladra ${ }^{127}$ \\
\hline Villar de la Yegua de la Ribera ${ }^{128}$ & Villar de la Yegua del Naso ${ }^{129}$ \\
\hline Villar de la Yegua del Sierro ${ }^{130}$ & Villar del Buey \\
\hline Viñuela & Xodies ${ }^{131}$ \\
\hline
\end{tabular}

Según el citado repartimiento de "peones y bestias" de 1484, vivían en dicha Tierra de Sayago un total de 1371 vecinos pecheros; siendo las poblaciones más importantes las de Almeida con 80 vecinos, seguida de Roelos y Pereruela, con 70 cada una, Villamor de Cadozos con 55 y Tamame, Carbellino y Bermillo con 50; y las menores las de Villardiegua del Nalso con uno, Pelazas y Fresno de Zamora ${ }^{132}$ con dos cada una, y Los Alcamines y Judiez con tres cada una.

116 Actualmene Pelazas, dehesa en Villar del Buey.

117 Actual despoblado de Piñolino en Piñuel.

118 Actualmente Piñuel.

119 Actualmente Roelos.

120 Actualmente Salce.

121 Actualmente La Cernecina.

122 Actualmente Sobradillo de Formariz, despoblado en Formariz.

123 Actualmente Torrefrades.

124 Despoblado de Carrascal.

125 Despoblado de Carrascal.

126 Actualmente Villamor de Cadozos.

127 Actualmente Villamor de la Ladre.

${ }^{28}$ Actualmente Villardiegua de la Ribera.

129 Actualmente Villardiegua del Nalso, dehesa en Roelos.

130 Actualmente Villardiegua del Sierro, dehesa en Cabañas de Sayago.

131 Actualmente Judiez, dehesa en San Román de los Infantes.

${ }^{132}$ Es una villa dependiente de una doble jurisdicción. Una cuarta parte de sus habitantes dependian de la ciudad de Zamora y el resto del obispo de dicha ciudad.

A. M. DEL BRio MATEOS: Una villa de señorio eclesiástico. Fresno de Sayago, siglos XIII-XIX. Madrid, 1986, pp. 30-35. 


\section{PODER ECLESIÁSTICO}

En un intento de magnificar su pasado histórico — del mismo modo que señalaban que su sinagoga había sido consultada sobre la muerte de Jesús dando una respuesta contraria a la misma, o que San Pablo había dirigido su epístola a los gentiles a la comunidad zamorana - varios cronistas e historiadores locales no dudaron en atribuir a la diócesis de Zamora un origen apostólico; lo que no deja de estar apartado de la realidad.

La restauración de Zamora por Alfonso III supuso, al mismo tiempo, el nacimiento de la diócesis; apareciendo ya en el 901 su primer obispo, Atila o Atilano.

Sin embargo, esta primera etapa diocesana va a ser breve pues en el 986 -último año en que se cita al obispo Salomón-, coincidiendo con las razias de Almanzor, el territorio diocesano zamorano se integra en gran medida en el de Astorga.

Antes de Alfonso III y desde el 986 hasta el siglo XII, la actual diócesis se repartía entre las de Braga, Astorga y Salamanca.

Tras unos años en que Jerónimo de Perigord encabeza al mismo tiempo las sedes zamorana y salmantina, en 1121, Zamora se convierte en obispado independiente, siendo su primer obispo Bernardo de Perigord "primus proprius episcopus zamorensis" 133; catorce años más tarde, en 1135, Alfonso VII, el gran benefactor de la iglesia de la ciudad, le donará el monasterio de Santo Tomé para futura sede catedralicia ${ }^{134}$.

En la denominada División o Hitación de Wamba, llevada a cabo en realidad en el siglo XII, pese a la atribución durante algún tiempo a la época visigoda, la diócesis aparece integrada por las Tierras del Pan, del Vino, Sayago, alfoz de Toro y una parte de Tierra de Campos: "Neumantia quam nostrates goti postea vocaverunt Cemoram tencat de Pena Gosendi usque ad Tornem super illos balneos de Valle de Rege usque Dorium; de Villale usque Oter de Fumos secus Rivulum Siccum usque Breto; de Tavara usque Dorim» ${ }^{135}$.

13:3 Así se le suele citar en la documentación.

En el muro de la catedral, junto a su tumba, figura la inscripción: "Primus zamorensis episcopus de modernis".

${ }^{34}$ G. Ramos de CAStRo: La catedral de Zamora. Fundación Ramos de Castro, Zamora, 1982, pp. 16-17.

ACZa., Legajo 8, $n^{0} 5$.

135 E. Fernandez-Paieto Dominguez y Losada: “Zamora, Diócesis de", Diccionario de Historia Eclesiástica de España. CSIC, Madrid, 1975, Tomo IV, p. 2799. 
También se delimita perfectamente la diócesís, en su extremo sur, en la concordia entre los obispos de Zamora y Salamanca, de $1185^{136}$.

Prácticamente, en ambos casos, estamos ante el mismo territorio que mantuvo hasta fines del siglo XIX, y que agrupaba los territorios concejiles de Zamora y Toro.

En varios documentos atribuidos a Alfonso III y Ordoño II se cita también el territorio de la diócesis zamorana.

El primero de ellos es la, a todas luces, falsa donación de Alfonso III a la catedral de Oviedo, del 906, en el que reparte entre ésta y la iglesia leonesa la totalidad de un extenso territorio astorgano entre el Carrión, Pisuerga y Zamora ${ }^{137}$.

Por lo que se refiere a la delimitación de la diócesis de León realizada por Ordoño II, en el 916, nos encontramos de nuevo ante un documento

Los límites señalados en la misma corresponden actualmente con: De Peñausende al río Tormes pasando por Ledesma, y desde a!li hasta el Duero; de Villalar a Tordehumos, junto a Medina de Ríoseco; desde allí hasta Bretó, y de esta población a Tábara y al Duero.

136 ACZa., Legajo 10 bis, $n^{\circ} 1$ (TZNa.), ff. LXIIr..-LXIIIr.

ACSa., Caja 14, Legajo $2, n^{0} 22$.

"... transegimus ita quod zemorensis ecclesia reddit salamantine VII ecclesias, que sunt in ual de Caneto: Torre de Petro Baroncel, Torres Menudas, Aldea de don Roderico, Aldea del Archo, Aldea de Imperatore, Cadreloros, Fradres, et illas alias acclesias que sunt ultra Tormes, scilicet, Ecla, Ezyna Sola, Barochopardo, Saldanya, quas eo tempore zemorensis ecclesia possidebat, et quicquid episcopalis iuris in ecclesiis ultra Tormes habebat, et abrenuntiat questioni del Aldea de Martin lustyz, et del Aldea de Martin Telez, et uille que dicitur Septem Ecclesies, et de Falfeyos, et de Penela, et questioni Castri de Ledesma et Fiscale Maioris. Et salamantina ecclesia similiter abrenunciat questioni proprietatis et possessionis Castri Nuny et questioni Balesse, et Fontis de Sanbuco, et de Cubo, et Fiscale Minorys, et questioni omnium aliarum ecclesiarum, que sunt in termino Ledesyno citra Tormes, vicelicet, Santiz, Palatios, Aldea Noua, Spino de Castello, Zemaion, Zemaniuncino, Ual de la Ossa, Spino, Santarem, Lauadima, Assamassa et Assamassa, et alia Assamassa, Furadelo, Zorita, et ecclesias de Maroleyas, Aldea Aldea (sic) de don Brun, Aldea de Dyago Romanez, Aldea de Pelay Nugez, Carrascal. Dauid Fereyrro, Aldea de Pelay Dient; et si que sunt alie in termino Ledesme, vel de nowo fuerint populate ad ius zemorensis ecclesie in perpetuum pertineant ita tamen ut si alique ecclesie infra terminos illarum septem ecclesiarum que sunt in ualle Caneti uel in terminis istarum uillarum, scilicet, Almenara, lusuado, Olmelos et Sant Pelagio et de nouo fuerint populate ad ius salamantine ecclesie pertineant, sopitis etiam in perpetuum omnibus questionibus, quas utraque ecclesias, ante diem huius transactionis, aduersus alteram agitaverant."

VV.AA.: Documentos de los Archivos Catedralicio y Diocesano de Salamanca (Siglos XII-XIII). Universidad de Salamanca, Salamanca, 1977, documento n²8, pp. 175-177.

J. L. Martín Martin: El Cabildo de la Catedral de Salamanca (Siglos XII-XIII). Centro de Estudios Salmantinos, Salamanca, 1975, pp. 73-74.

${ }^{+37}$ ACLe., Fondo Particular, $n^{\circ} 348$.

Existen varios documentos más en el Archivo de la Catedral de Oviedo.

G. DEL SER QuiJANo: Documentación de la Catedral de León (Siglos I $X$ - $X$ ). Universidad de Salamanca, Salamanca, 1981 , documento $n^{\circ} 5$. 
falso, pues es una copia literal ampliada de otro de Ordoño III, del 955. En ambos documentos - original y falso- se señalan como límites leoneses en relación a la diócesis y actual provincia zamorana ${ }^{138}$ : "Ideo offero sacro sancto altario ecclesias diocesanas: in primis per terminum de Astorica; et inde per terminum de Zamora, quod est Castrum Gunsalvo iben Muza; et per terminum de Tauro et per terminum Septemmankas ... usque in Castro Viride ...".

Más tarde dona: "In Campis Gotorum, hec sunt: in Verrot Zancos, quod est Castrum Viride cum villulis suis: Carlon et Quintanella, Ratores, Romeses, Sancta Maria».

El cabildo comienza a organizarse al mismo tiempo que se nombraba al primero obispo de la restauración - don Bernardo de Perigord-, aunque es de suponer que durante todo el siglo XI tuviera su antecedente en la institución colegial que funcionaria en la ciudad.

En el siglo XIII adquiere su estructura organizativa, integrada por 24 canónigos y 12 porcionarios ${ }^{139}$. Existiendo una categoría dominante dentro del conjunto, la de las «dignidades" o «personas", en la que se incluian el deán, el chantre, el tesorero, el maestrescuela y los arcedianos de Toro y Zamora ${ }^{140}$.

Los miembros del cabildo aparecen realizando vida en comunidad, por lo que son frecuentes términos como "convento" al referirse a los mismos en el siglo XII: "una cum conventu eiusdem ecclesie canonicorum" ${ }^{141}$ o "volumus ego Stefanus, Dei permissu zemorensis episcopus, omnisque Sancti Salvatoris conventus ..." ${ }^{142}$.

Cabildo que goza de la protección regia tanto en sus personas como bienes, como hace patente Fernando III en los primeros años de su reinado: "Sapiatis quod ego recipio in mea garda et in mea comenda totum quantum habet capitulum canonicorum de Çamora" ${ }^{143}$.

138 F. FerRero FerRero: "Delimitación de la diócesis de Zamora". Civitas. MC aniversario de la ciudad de Zamora. Zamora, 1993, p. 128.

ACZa., Legajo 8, no 1.

Existen diversas copias en el Archivo de la Catedral de León.

139 M. Sánchez Rodriguez: Constitutiones Capituli Ecclesiae Zamorensis. Salamanca, 1988, p. 17.

"Item, quod, pro posse suo, numerus XXIII cr canonicorum et XII portionariorum, qui statutus est in ecclesia zamorensi, non augmentabitur».

140 loidern.

$141 \quad A C Z a .$, Legajo 13, $n^{\circ} 4$.

142 ACZa., Legajo 13, $n^{\circ} 27$.

143 ACZa., Legajo 8, nº 16. 
Pero a fines de ese siglo XII comienza a haber un alejamiento de la vida en comunidad, a la vez que se incrementa la relajación de la regla canónica. Proceso que lleva a una desorganización beneficial y económica ${ }^{144}$.

Eso va a ocasionar que los papas en el siglo XIII intenten dar una organización estable a los cabildos, mediante la redacción y aprobación de Constituciones capitulares, de lo que se conservan numerosos ejemplos en Castilla y León entre 1224 y $1245^{145}$.

La particularidad de las Constituciones zamoranas estriba en que no son verticales, es decir, otorgadas por la Santa Sede, sino horizontales, o, lo que es lo mismo, fueron realizadas directamente por el cabildo zamorano, en un proceso que abarca, principalmente, de 1219 a 1286, bajo los mandatos episcopales de Martín II, Pedro I y Suero Pérez ${ }^{146}$.

Con ellas, la iglesia zamorana perfecciona su estructura organizativa, su estatus jurídico - tanto interno como externo-y se reorganiza económicamente, en una mejora manifiesta de su gestión.

Se consolida así la iglesia como una gran institución de poder dentro de la vida de la ciudad y de su tierra. Y el cabildo, formado por clérigos privilegiados, se manifiesta ya de forma clara como una institución representativa de la jerarquia eclesiástica local, adscrita al bloque social dominante ${ }^{147}$.

A su estructura organizativa ya nos hemos referido someramente, y no consideramos necesario hacer nuevas referencias.

Las constituciones, como hemos apuntado, son un jalón más en la autonomía judicial de que gozaba la iglesia zamorana.

Sin entrar a tratar el tema de la potestad de impartir justicia a sus vasallos y a los que trabajan las tierras de la iglesia, ya tratado por José Luis Martín en su ponencia ${ }^{148}$, y que será fuente de graves conflictos, como luego veremos; lo cierto es que los eclesiásticos, desde la restauración de la diócesis en 1121, escapan cada vez más al control judicial civil.

${ }^{144}$ J. C. DE LeRA MAIlLo: “Libro de las Constituciones de la Iglesia de Zamora». Civitas. MC aniversario de la ciudad de Zamora. Zamora, 1993, p. 167.

145. Ibidem.

146 Ibidem.

M. SÁnchez Rodriguez: Constitutiones..., pp. XI-XII.

147 J. C. DE Lera MAILlo: “Propiedad urbana del cabildo de Zamora en el siglo XIV". Primer Congreso de Historia de Zamora. Tomo III: Medieval y Moderna. Instituto de Estudios Zamoranos, Zamora, 1991, p. 375.

148 Ponencia sobre el tema «El fuero de Zamora j’ los fueros-contratos agrarios». 
Por ello no debe sorprendernos que, entre las actuaciones de Martín 1 figure, en 1215, posiblemente ante el peligro que suponía el fuero zamorano, la confirmación, a petición de los clérigos, de los usos y libertades que tenían éstos al comienzo de su episcopado, entre ellas la inmunidad frente al poder secular ${ }^{149}$.

$Y$ tampoco que las Constituciones se conviertan en un auténtico código interno. Cómo entender sino que las heridas con arma entre miembros del cabildo se castiguen con 60 dias de privación de ración y expulsión del coro, escapando de la jurisdicción civil ${ }^{150}$.

Cabildo y obispo zamoranos fueron acumulando un enorme patrimonio económico mediante métodos adquisitivos gratuitos, tales como donaciones, testamentos, abandono de derechos; onerosos, principalmente compra-ventas y cambios; e inversiones productivas.

A las grandes donaciones regias tras la constitución de la diócesis se unen las tareas repobladoras en el territorio diocesano, en los siglos XII y XIII, logrando grandes extensiones de tierra y una gran número de vasallos.

Simultáneamente, se irán produciendo adquisiones menores de particulares y la recaudación de impuestos, derechos y diezmos, que permitirán grandes inversiones en los siglos siguientes.

Se va configurando un territorio de señorío, tanto episcopal como capitular, que se distribuye por las Tierras del Pan, del Vino y Sayago.

Limitándonos a estos territorios, aunque con algunas oscilaciones temporales por el cambio de jurisdicción de algunos lugares, podemos señalar que a fines del siglo $X V$, pertenecían a la iglesia ${ }^{151}$ :

\section{- Al obispo:}

- Fermoselle, con sus aldeas de Pinilla de Fermoselle, Fornillos de Fermoselle y Cibanal.

-- Almendra.

149 ACZa., Legajo 33, nº 33.

"Adicimus etiam ut nullus regum vel principum terrenorum vel eorum vicariorum vel quelibet secularis potestas in eorum rebus tam in vita quam in morte habeat potestatem".

${ }_{150}$ M. SÁnchez Rodríguez: Constituciones..., pp. XV-XVII y Cuadro Sinóptico del Derecho Penal.

151 A. Moneno Sebastian: Los señorios de la Iglesia en la tierra de Zamora, siglos XVI-XIX. Los procesos desamortizadores de la riqueza señorial. Zamora, 1984, pp. 49-51. 
- Fresno de Sayago ${ }^{152}$.

- Manganeses de la Lampreana.

- Mayalde.

- Moraleja de Sayago.

- Venialbo.

- Villalcampo

- Al cabildo:

- Avedillo.

- Bamba.

- San Román de los Infantes.

- Sanzoles.

Hasta el año 1266 los bienes pertenecientes al obispo y al cabildo estaban unidos y eran explotados económicamente de forma conjunta. En esa fecha - más tardía que en las diócesis vecinas - se divide su administración en dos "mesas" - la episcopal y la capitular - tras dos arbitrajes en los que se hizo frente a los aspectos que podian ser más conflictivos ${ }^{153}$.

Los bienes episcopales, por su carácter dependiente de una sola cabeza, no supusieron problema en cuanto a su administración, no ocurriendo lo mismo con los capitulares.

Tanto antes como después fueron gestionados mediante la que es denominada "explotación individualizada".

Como ha señalado José Carlos de Lera para el caso de Zamora ${ }^{154}$, el cabildo distribuía por asignación entre sus miembros todos sus bienes, transfiriendo la responsabilidad personal de los mismos, cediendo el dominio directo y reservándose el dominio eminente sobre las propiedades; recibiendo una cantidad determinada a cambio; ellos a su vez cedían el dominio útil mediante subarriendo.

152 Es de señorío compartido con la ciudad de Zamora.

A. M. DEL BRIO MATEOS: Opus cit., pp. 30-35.

153 J. SÁNCHEZ HERRERO: "Las instituciones eclesiásticas de la diócesis de Zamora durante la Edad Media, siglos VII al XV». Civitas. MC aniversario de la ciudad de Zamora, p. 56.

${ }^{154}$ J. C. DE LERA MAILlO: "Propiedad urbana...", p. 379. 
En la segunda mitad del siglo XIV, como consecuencia, sin duda, de las convulsiones económicas que se viven en esos momentos, se produce un cambio en el sistema de gestión de los bienes capitulares, aunque se mantenga una fase puente hasta los primeros años del siglo XV ${ }^{155}$.

Se pasa así a una "gestíón colectiva" o "corporativa", en la que el cabildo como institución es el que cede directamente el dominio útil de sus posesiones a los arrendatarios, desapareciendo el protagonismo de los prebendados como intermediarios. La institución capitular se reserva así los dominios útiles y directos. Los capitulares recibirán una parte proporcional a los beneficios obtenidos por la "mesa» ${ }^{156}$.

Aunque nos hemos circunscrito al hablar del poder eclesiástico, por la propia limitación que este ciclo de conferencias impone, al obispo y al cabildo zamorano, no podemos olvidar a otras diócesis, a las órdenes monásticas $o$ a las órdenes militares, cuyos señoríos se desarrollaban por los espacios urbanos a los que nos hemos estado refiriendo.

Baste pues esta pequeña relación que sigue para quedar constancia de las mismas ${ }^{157}$ :

- Señoríos del arzobispo de Santiago:

- Arquillinos.

- Señoríos de órdenes monásticas:

- Monasterio de Valparaíso:

- El Cubo y El Cubeto.

- Moreruela:

- La actual Granja de Moreruela.

- Señoríos de órdenes militares:

- Orden de Santiago:

- San Cebrián de Castro, Olmillos de Castro, Perilla de Castro, Piedrahita de Castro, Fontanillas de Castro, San Pelayo de Castro, Villafáfila, Revellinos, San Agustín y Peñausende.

155 F. Ferrero Ferrero: Rentas del Cabildo Catedral de Zamora en el siglo XV. Análisis del Libro de Rentas de 1446-1451. (Memoria de Licenciatura). Salamanca, 1980.

F. Ferrero Ferrero: "El Libro de Rentas de la Catedral de Zamora". Civitas. MC aniversario de la ciudad de Zamora, p. 169.

156 Ibidem.

J. C. DE LERA: «Propiedad urbana...», p. 379.

157 A. Moreno Sebastian: Opus cit., pp. 47-51. 
- Orden de San Juan de Jerusalén:

- Vidayanes y Fuentespreadas.

\section{CONFLICTIVIDAD JURISDICCIONAL}

La conflictividad por temas jurisdiccionales fue muy intensa a lo largo de toda la Baja Edad Media, teniendo que enfrentarse el concejo zamorano a diversos pleitos y a la firma de numerosas concordias por dicho aspecto.

Fundamentalmente esos conflictos se van a producir con la iglesia; siendo también muy frecuentes los mantenidos con Toro, mientras que son prácticamente inexistentes, tal vez, por la presencia de unos límites geográficos muy claros, los sostenidos con otros concejos, como el de Salamanca. Tampoco abundan los que enfrentaron a Zamora con señoríos laicos.

\section{a) Conflictos entre el concejo y la iglesia}

La conflictividad entre el concejo y la iglesia zamoranos fue intensa a lo largo del siglo XIII, como ha puesto de manifiesto Coria Colino ${ }^{158}$, en parte, por la oposición de intereses de ambas instituciones, pese a la necesaria coexistencia y equilibrio de fuerzas de las mismas ${ }^{159}$.

A lo largo de la segunda mitad del siglo XIII, coincidiendo con el episcopado de don Suero Pérez, se va a desarrollar un largo pleito, al que no es ajeno el creciente intervencionismo regio en la vida concejil.

Pleito que, en gran parte, tiene su origen en la composición de 1232 , confirmada por Fernando III, en relación a los oficios concejiles, en la que se hace patente la presencia de oligarquías urbanas, controlando el poder y la administración municipal ${ }^{160}$.

${ }^{158}$ J. I. CORIA COLINO: «El pleito entre cabildo y concejo zamoranos de 1278: Análisis de la conflictividad jurisdiccional. Concejo, cabildo y rey". Primer Congreso de Historia de Zamora. Tomo III: Medieval y Moderna. Instituto de Estudios Zamoranos, Zamora, 1991, p. 285.

159 A. SACRIStán MARTinez: Municipalidades de Castilla y León. Instituto de Administración Local, Madrid, 1980.

160 J. I. Coria Colino: Opus cit., p. 285.

S. Moreta Velayos y A. Vaca: “Los concejos urbanos, núcleos de señoríos corporativos conflictivos. Aproximación a las relaciones entre oligarquia urbana y campesina en Zamora y su tierra, siglo XV', Agricultura y sociedad, $n^{\circ} 23,1982$, pp. 343-385. Señalaban esa presencia en la segunda mitad del siglo XIII. 
En dicha composición se da paso, del concejo «abierto» instituido tras la repoblación urbana, a uno "reducido" o "restringido", pues se establece que en la ciudad haya 16 jueces - ocho de los "milites" y ocho del concejo-, junto con dos nombrados por el rey y otro por el obispo, con un mandato anual ${ }^{161}$ : "... octo de militibus et octo de concilio, et duo ex parte regis, et unus ex parte episcopi ...»162.

Estructura que se mantiene en gran medida en la creación del regimiento perpetuo por Alfonso XI, en 1342, en que se establece que haya 16 regidores, ocho "de parte del concejo" y otros ocho "de parte de los caballeros", que gobernarian por un tiempo ilimitado la ciudad en unión de un juez real y de los alcaldes y su notarios ${ }^{163}$.

Como ha señalado Coria Colino ${ }^{164}$, la participación de un juez de la iglesia en los concejos urbanos no es privativa de Zamora, ya que puede observarse en aquellos que reciben el Liber.

La figura del juez eclesiástico es además más antigua que la concordia de Fernando III, estando ya contrastada en el reinado de Alfonso IX, durante el que se señala que había "un ome bono de sua eglesia por juyz, que iuzgasse e fuesse con los otros juyzes en los pleitos de la villa e iuzgava e levava sua parte de las calomnas e de las otras cosas, assi commo cada uno de los otros juyzes de la villa" ${ }^{165}$.

Como bien ha señalado Coria, no estamos ante un juez que juzgaba alzadas, sino ante uno más de los del concejo, con los que actuaba colegiadamente ${ }^{166}$.

El conflicto concejo-iglesia se va a poner de manifiesto en el momento en que el rey aumente su intervencionismo en la vida municipal a través de la figura de los jueces de afuera o de salario.

La introducción de ese juez real, que alteraba el antiguo orden concejil, pues rompe la colegialidad y aparece en un puesto de preeminencia sobre los demás, va a ser la ocasión que aprovecha el concejo para eliminar al juez eclesiástico, y así se expresa en la alegación que realiza la ciudad

\footnotetext{
161 F. Ferrero Ferrero: “Creación del Regimiento Perpetuo", Civitas, MC aniversario de la ciuclad de Zamora. Zamora, 1993, p. 92

162 J. Gonzalez: Reinado y Diploma de Fernando III. Diplomas 1217-1232. Monte de Piedad y Caja de Ahorros de Córdoba, Córdoba, 1980.

163 AHPZa:: Sección Municipal: Zamora. Libro n² 267 (Tumbo Municipal), ff. 9v-12r.

F. Ferrefo Ferrero: "Creación del Regimiento...", p. 92

${ }^{164}$ J. I. Coria Colino: Opus cit., p. 286

165 ACZa., Legajo 9, n 17.

166 J. I. Coria Colino: Opus cit., p. 287.
} 
ante el infante don Sancho, en 1278: "A la tercera cosa que dizíe el obispo e el cabildo que avien de aver un su iuez clérigo de la su eglesia que hy iudgasse con los otros sus iuzes de la villa, dixo Gutier Pérez e los otros bonos omes que verdad era que avíe hy un iuez clérigo de la eglesia, mas esto que era quando avie en la villa iuezes del fuero, e agora non avie y iuzes del fuero, mas que Gutier Pérez era hy iuez por el rey e que por esta razón non avie hy a aver iuez de la eglesia" 167.

El procedimiento judicial se inicia en 1272 , al presentar la iglesia de Zamora su protesta por este hecho ante Alfonso X, quien determina, estando en Burgos, el 10 de septiembre de 1272, que se restituya al juez eclesiástico así como que «lieve sua parte de las calomnas e de todas las otras cosas que acaeçieren, asi commo a cada uno de vos los otros juyzes» ${ }^{168}$.

Aunque asigna un plazo de dos meses - hasta San Martín- para que el concejo presente las alegaciones que estime pertinentes, éste acepta en su totalidad el mandato real, señalando incluso "que quanto se contenía en la letra del rey que era verdat e que non querían dezir contra la letra ninguna cosa, nin aver pleito con el bispo nin con el cabildo, e que les plazía que el obispo e el cabildo pussiesen un juiz que iulgasse con los otros e oviese parte en las calomnas, ca asi lo solian fazer» 169 .

La iglesia, tras ello, presentó por juez al canónigo Pero Vicéntez ${ }^{170}$.

Sin embargo, no parece que el nombramiento se hiciera efectivo, ya que, en julio de 1278, se lleva a cabo una copia notarial de dicha provisión, sin duda para presentarla como prueba de la contumacia concejil ante el infante Sancho, a quien se acude en esas fechas en petición de justicia.

Previamente, en 1275, el infante Fernando, por las peticiones de la iglesia, confirmaba la provisión de Alfonso $X^{171}$.

En dicho pleito ante don Sancho, el cabildo alega que el juez real - Gutier Pérez - y el concejo impiden la presencia del representante de la iglesia ${ }^{172}$.

\footnotetext{
187 ACZa., Legajos 9, no 25; y 14, no 1 .

16 ACZa., Legajo 9, no 17.

169 Ibidem.

170 lbidem.

171 ACZa., Legajo 10bis, $n^{\circ} 2$ (TBZa.), ff. 18v-19r.

172 ACZa., Legajos 9, no 25; y 14, no 1 .
} 
Ya conocemos la respuesta concejil: Eso era cuando en Zamora existían jueces de fuero y en esos momentos ya no había ${ }^{173}$.

El futuro Sancho IV determina que se mantenga el juez eclesiástico ${ }^{174}$.

Esta sentencia inicial es apelada por el concejo zamorano, por lo que son citados representantes de ambas partes a hacer nuevas alegaciones, siendo el propio don Suero - demostrando el interés que tenía en el asunto- quien va a representar personalmente a la iglesia, reafirmándose las dos partes en lo ya señalado. Por ello el rey confirma la sentencia ${ }^{175}$.

Sin embargo, poca fuerza hubo de tener ésta pues, en fecha indeterminada pero posterior a la misma, cabildo y concejo llegan a un acuerdo para poner fin al conflicto, en que acuerdan ${ }^{176}$ :

"Otrossi, que los vassallos del obispo e del cabildo e de las eclesias e de los clérigos non den en la soldada del juyz de Çamora, ca nunca lo dieron a los otros juyzes que furon ante deste Gutier Pérez. E asi lo mandó el rey por sus cartas. E aquelo que delos tomaron por esta razón que ge lo entreguen todo".

"Otrossi, que el obispo e el cabildo ayan so juyz compannero de ssua eglesia que iudgue e huse de so offiçio e lieve su parte de las calopnias con os otros juyzes de Çamora, assí commo solían e commo manda el privilegio del rey don Fernando".

Paralelamente a este enfrentamiento se produce otro, por causas semejantes, que afecta a la tierra de Zamora y a diversos lugares del obispo y del cabildo.

Como ha señalado José Luis Martín ${ }^{177}$, el concejo y los jueces zamoranos van a negar el derecho de los clérigos a juzgar a sus vasallos 0 , sin negarlo, van a actuar en su contra, al considerar nulos los juicios ecle-

$1 / 3$ Ibidem.

14 Ibidem.

"Ctrossi, mandé que el juez de su eglesia que lo oviessen assi commo sienpre ovieron".

175 lbidem.

"...yudgo e mando que el obispo e el cabildo pongan e ayan un juez clérigo que iudgue los pleytos que antel vinieren, assi como los otros juezes de la villa, e aya su parte de las calonnas assi como uno dellos, e no sea embargado por razón que Gutier Pérez es iuez en Camora del rey, nin porque los otros iuezes ayudan a Gutier Pérz a yudgar los pleytos por mandado del rey, nin porque non sean tantos quantos manda su fuero".

176 ACZa., Legajo 16, 3ำ parte, $n^{0} 2$.

17 J. L. Martin Rodriguez: Campesinos vasallos del obispo Suero de Zamora (1254-1286). Universidad de Salamanca, Colegio Universitario de Zamora, Salamanca, 1981, p. 20. 
siásticos, al acoger en la ciudad a condenados por malhechores, al conocer "otra vegada de las malfetrías" y no entregarlos; al hacer prisioneros a los que actuan como jueces eclesiásticos y llegar a darles muerte.

El pleito, simultáneo al anterior, se basa en las siguientes acusaciones de la iglesia zamorana hacia el concejo ${ }^{178}$ :

1. La iglesia tenía sus jueces en las villas y lugares episcopales y capitulares desde tiempo inmemorial, y que el juez real Gutier Pérez, en unión de otros oficiales concejiles y hombres buenos de Zamora, fueron a San Martín de Bamba, donde mataron a dos jueces eclesiásticos, y mandaron que desde entonces no hubiera ningún otro en dichos lugares.

2. Gutier Pérez y el concejo zamorano ocuparon Carrascal, lugar episcopal, a escasos kilómetros de Zamora, donado a la iglesia por Bartolomé Ribera ${ }^{179}$. El asalto se produjo al morir éste sin hijos.

3. Gutier Pérez y el concejo zamorano derribaron las escaleras que el obispo y los canónigos tenían para descender desde sus casas a sus bodegas y huertos, en la zona de las Peñas de Santa Marta.

4. El dicho Gutier Pérez y el concejo zamorano asaltaron la villa episcopal de Manganeses de la Lampreana, robando y destruyendo cuanto encontraron a su paso.

5. Gutier Pérez hacía pechar en su soldada - cosa que nunca se había producido con anterioridad- a los vasallos del obispo y del cabildo que moraban en aldeas y lugares episcopales y capitulares.

La primera de ellas - sin duda, la más grave de las acusaciones-, como ha señalado José Luis Martín ${ }^{180}$, se concreta el 4 de abril de 1275 al no permitir el tantas veces citado Gutier Pérez el derecho episcopal de "meter sus juyzes en San Martín de Bamba e en Bamba e en Sancta María del Valle e en otros lugares suyos e de sua eglesia e estos judgavan los preitos a los sus vassallos e fazían la justicia temporal". En el enfrentamiento murieron Domingo Román y Pedro Fijo, jueces de la iglesia en la primera de dichas poblaciones, que fueron ejecutados mientras el pregonero anunciaba que sufrirían igual pena "todos los otros que [se] llamasen

\footnotetext{
178 ACZa., Legajos 9, $n^{9} 25 ;$ y $14, n^{\circ} 1$.

179 Lo dona, en unión de su esposa María Centeno, el 11 de diciembre de 1275, junto a todo lo que poseian en Villalube, como reconocimiento de la cesión en préstamo vitalicio del cillero de Santa Maria del Valle.

ACZa., Leg. 10 bis, $n^{\circ} 2$ (TBZa.), ff. 45v-51v

Cfr. J. L. Martin Rodriguez: "El cillero de Santa Maria del Valle. Una "empresa" señorial zamorana del siglo XIII». Stvdia Zamorensia, II, 1981, pp. 67-85.

180 J. L. Martin Rodríguez: "Campesinos...", p. 20.
} 
juyzes de sus lugares de la eglesia»; por último, el oficial nombrado para Santa María del Valle, fue hecho prisionero cuando estaba a la puerta de la catedral zamorana y encarcelado ${ }^{181}$

A estas graves acusaciones, el concejo zamorano respondió que ${ }^{182}$ :

1. El obispo no debía tener jueces en San Martín de Bamba ni en ningún otro lugar, ni los había tenido nunca, sino que debía tener jurados, que, por tanto, estarían sujetos a las autoridades concejiles ${ }^{183}$.

2. Carrascal era de un hombre bueno que murió sin herederos y que el rey mandó a Gutier Pérez que tomará dicho lugar.

3. Las escaleras se derribaron por mandato real "et que assi derribarien la puente de la villa si ge lo el rey mandasse". Además indicaron que las escaleras eran de propiedad regia.

4. Gutier Pérez señaló que era verdad que el concejo zamorano fue a Manganeses, pero que lo hizo en son de paz y que si algún hombre cometió daños que sería castigado.

5. Siempre que habia habido juez real en Zamora se había hecho pechar para el pago de su salario a los vasallos episcopales y capitulares.

6. Por último, señalaron que no eran culpables de los daños y sacrilegios de los que les acusaba el obispo.

El rey sentenció que ${ }^{184}$ :

A) Era verdad que Carrascal pertenecía al obispo zamorano y que fue asaltado, por lo que manda que le sea devuelto el lugar.

B) Fueron ciertos los daños en Manganeses; teniendo que reparar lo dañado o devolver lo robado las personas que hicieron el daño si se conoce su personalidad, siendo responsable subsidiario el concejo.

El resto de los casos denunciados pasan a ser estudiados por los jueces pesquisidores, decidiendo el rey más tarde que ${ }^{185}$.

\footnotetext{
18. ACZa., Legajo 10 bis, $n^{\circ} 2$ (TBZa.), ff. 18r-v., 19r-v., 19v-20r.

182 ACZa., Legajos 9, n²5; y 14, no 1 .

iв3 M. T. Gacto FERnANDEZ: Estructura de la población de la Extremadura leonesa. CSIC, Salamanca, 1977 , p. 140.

Señala que los jurados eran afuncionarios de las aldeas que, elegidos por los alcaldes de la villa, desempeñaban funciones judiciales y de vigilancia».

Cfr. J. I. CoRia Colino: Opus cit., p. 289.

184 ACZa., Legajos 9, nº 25; y 14, $n^{0} 1$.

185 Ibidem.
} 
A) Siempre tuvieron el obispo y el cabildo sus jueces, que nunca fueron jurados, en San Martín de Bamba y en los otros lugares y que así deberían seguir teniéndolos.

B) Las escaleras ya las tenían en el reinado de Fernando III, y que por tanto tenían que respetárselas.

C) Los vasallos de la iglesia quedaban exentos del pago de la soldada del juez real, como siempre lo estuvieron.

$Y$ en igual sentido se reafirma la sentencia tras las correspondientes apelaciones concejiles.

Al mismo tiempo, y como compensación a los actos sacrílegos y otros daños, se condena al concejo al pago de 1.000 maravedís de la moneda nueva, que equivalian a $6.000 \mathrm{mrs}$. de la moneda de la guerra.

Paralelo a este pleito, según ha estudiado José Luis Martín ${ }^{186}$, se desarrolla otro contra el concejo zamorano, también ante el infante Sancho, sobre el que pronuncia sentencia en 1279.

Los temás están en muchos casos relacionados con el anterior y en todos ellos reciben unas respuestas favorables las demandas del obispo, que pueden resumirse en las siguientes:

- Que no recibiera el concejo yantares en los lugares de la iglesia.

- Que los juicios contra los clérigos fuesen juzgados por el obispo y los jueces eclesiásticos.

- Que reconocieran a la iglesia el derecho a "a ganar e aver heredamientos de todo omne».

- Que no se opusieran a la excomunión o a las penas eclesiásticas dictadas por el obispo contra los habitantes de Zamora. iglesia.

- Que no tomaran represalias contra los hombres y vasallos de la

- Que no prendieran a los clérigos salvo por orden del obispo, y que en ningún caso los llevaran a la prisión del concejo ni les dieran muerte; que fueran entregados a los jueces eclesiásticos.

- Que los oficiales del concejo no entraran a tomar prendas en las casas de los clérigos y que respetaran la inviolabilidad de las iglesias.

- Que los ganados de los miembros de la iglesia zamorana pudieran pastar en los pastos comunales.

186 J. L. Martin Rodriguez: “Campesinos...”, p. 21. 
- Que los pleitos por testamentos se siguieran, como hasta entonces había sido, por los jueces eclesiásticos.

- Que los clérigos pudieran tener los "salidos" de sus casas sobre las murallas de la ciudad.

- Que los miembros de la iglesia de Zamora pudieran entrar y salir por la puerta del Mercadillo el Domingo de Ramos para la procesión y representación de Ramos.

Tanto esta resolución judicial como la anteriormente citada dudamos que verdaderamente fueran cumplidas, ya que el obispo don Suero en su "Apologia» no hace la menor referencia a las mismas. Además, el acuerdo entre el cabildo y el concejo, al que en su momento nos hemos referido, realizado posiblemente en el primer tercio del siglo XIV ${ }^{187}$, intenta poner fin a todos estos temas, que seguian pendientes desde el año 1274 según que en el mismo se señala ${ }^{188}$.

Sin embargo, el obispo no parece conformarse con un acuerdo que le es totalmente favorable y deja en el aire un último interrogante ${ }^{189}$ :

"Otrossí, dizen el obispo que quier saber qué emienda farán e que ondra a él e a sancta eglesia por las desondras e por los quebrantamientos de las eglesias e de las villas e por las prisiones e por las muertes de los clérigos e por las personas de la sancta eglesia e por las piérdedas e por los dannos e por los menoscabos que han recebido el obispo e los clérigos e los vassallos. E quando elos hy tomaren mesura el obispo tomará hy tal timpla e mesura porque elos se tengan que les faz mucha ondra e mucha graçia".

Paralelamente a estos enfrentamientos concejo-iglesia, se producen otros conflictos por el control del territorio.

El concejo zamorano no parece dispuesto, según avanza el siglo XIII, a seguir perdiendo lugares de su tierra - o, al menos, el control indirecto sobre los mismos, que pasan a manos del obispo o del cabildo.

El ejemplo más claro, posiblemente, sea el de Fermoselle.

El concejo zamorano poseía desde, al menos, el siglo XII, el privilegio de que doce postores del lugar le hicieran foro, como ya se señala en la donación que hace de dicha villa Alfonso IX al obispo Martín I en $1205^{190}$.

187 ACZa., Legajo 16, $3^{a}$ parte, $n^{9} 2$.

${ }^{188}$ Ibidem.

189 Ibidem

190 “... cum ipso castello et cum suis pertinenciis et directuris, exceptis illis duodecim postariis qui cum concilio de Zemora solent facere forum". 
El malestar que dicha entrega debió producir en la institución concejil zamorana fue la posible causa de su vuelta al poder regio, aunque igualmente pudo influir su posición estratégica ${ }^{191}$.

Alfonso IX va a ser también quien le otorgue fuero a Fermoselle en 1221 , en el cual, además de exigir a sus moradores, entre otros aspectos, un foro anual de un maravedi y de acudir a las armas en caso de guerra con Portugal, se confirma el acuerdo de los concejos de Fermoselle y de Zamora respecto a los doce postores. No obstante, este aspecto se anularía en los períodos de guerra con Portugal, posible concesión zamorana al rey en el momento de reintegración de la villa a la corona ${ }^{192}$.

Alfonso $X$ entregará de nuevo, en 1256, la villa con su ciurisdictione temporali» a la iglesia zamorana en la persona de su notario mayor para el reino de León, el obispo don Suero, casi en iguales términos en que la había donado Alfonso IX, pues excluye de ella "los doze postores que el conceyo de Zamora ha en la sobredicha uilla" ${ }^{193}$.

La importancia de esta donación es tan obvia que don Suero no duda en encabezar su orgullosa "Apología" con dicha adquisición cuando aún no había tomado posesión de la sede episcopal: "Primeramientre luego que fu confirmado en obispo, ganó la uilla de Fremoselle del rey don Alfonso. Primo igitur tempore electionis mee confirmate acquisivi a domno rege Alfonso villam de Fremosele, cum omni iurisdictione temporali quam ibidem predictus rex habebat" ${ }^{194 .}$

Iniciando una tarea de restauración arquitectónica y agrícola, en consonancia con la importancia del lugar, que reportaba a la iglesia zamorana

ACZa., Legajo 10 bis, ํo 2 (TBZa.), f. 86v.; y Leg. 15, nº 1 .

El documento está otorgado en El Piñero el 17 de diciembre de 1205.

Cfr. M. SANCHEZ RodRiguez: Fueros y posturas..., p. 72.

191 M. SANChez Rodriguez: Fueros y posturas..., p. 72.

192 "Concedimus etiam uobis et confirmamus forum vestrum quod habetis cum concilio de Cemora, videlicet: Quod detis eis XII postores, sicut soletis, pro ad collectam et fossatum sive hostem, tam contra mauros quam contra aliam partem. Et de magis vobis non demandent... Si uero aliquando contigerit me aut successores meos mouere exercitum in Portugaliam, debetis toti venire in meam hostem. Sed contra aliam partem no debetis dare nisi XII postores concilio de Zamora, ut supra dictum est's.

ACZa., Legajo 10bis, $n^{0} 2$ (TBZa.), ff. 92v-93r y 94r-v.; y Legajo $15, n^{2} 7$

AHPZa.: Sección Municipal: Zamora, Leg. XVI, no 3 .

M. SÁnchez Rodriguez: Fueros y posturas..., p. 75.

J. Rodriguez Fernández: Opus cit., p. 333.

${ }_{193}$ ACZa., Legajo 10 bis, $n=2$ (TBZa.), ff. 86v-87r. y $96 r-v$.

M. SANCHEZ RODRIGUEZ: Fueros y posturas..., p. 72.

J. L. Martín Rodriguez: "Campesinos...", p. 11.

194 ACZa., Legajo 10 bis, № 2 (TBZa.), f. 162r. 
quinientos vasallos: "Vbi, postquam fui episcopus, feci fieri bonas domos et plantavi vineas et emi ortos ibi et feci alios in quibus feci plantari diversa et multa arborum genera" 195 .

Un mes más tarde de la donación real, como consecuencia, posiblemente, de la influencia de don Suero ante la corte, voluntariamente o presionado, como ha señalado José Luis Martín ${ }^{196}$, el concejo zamorano cede al obispo sus derechos sobre los 12 postores y el señorío y jurisdicción que poseía en dicho lugar, aunque reservándose el yantar que se ofrecía a los junteros de Zamora, cuando acudian a celebrar junta en Fermoselle ${ }^{197}$.

Pero pronto surgieron los conflictos, pues ambas donaciones fueron impugnadas.

Los fermosellanos se opusieron a su paso a la dependencia episcopal, intentando que el rey anulara la donación, de la que se enteraron solamente dos días antes de que el monarca la hiciera efectiva. Entrega que se llevó a cabo, aunque el obispo se viera obligado a prometerles y hacerles "mucha ondra e mucho bien e que uos guarde uuestros fueros $e$ unestros privilegios» ${ }^{198}$.

Por ello fue necesario un nuevo documento real, en el mes de junio, para que los habitantes de la villa aceptaran al nuevo señor ${ }^{199}$.

El concejo zamorano, por su parte, pronto dio marcha atrás en su acuerdo y, aprovechando un viaje de don Suero a la corte, atacó Fermoselle, expulsando a los hombres del obispo y derribando casas, talando árboles y arrasando las cosechas almacenadas en los silos episcopales ${ }^{200}$.

El obispo, como era de esperar, acude al amparo real en demanda de justicia, comprobándose por los jueces pesquisidores que los hechos eran ciertos, razón por la que es condenado el concejo zamorano ${ }^{201}$.

Ante la resistencia que ofrece el concejo de Zamora a cumplir la sentencia, Alfonso X le amenaza con llevar a sus miembros a prisión: "mandamos a este nostro portero Domingo Rodríguez que se lo uos assi non

195 Ibidem

196 J. L. Martín Rodriguez: "Campesinos...", p. 12.

197 Ibidem.

ACZa., Legajo 10 bis, $n^{\circ} 2$ (TBZa.), \#f. 87v-88r; y Leg. $15 n^{\circ} 3$. Se realiza el último domingo de mayo de 1256.

198 ACZa., Legajo 10 bis, $n^{\circ} 2$ (TBZa.), f. $88 \mathrm{r}-\mathrm{v}$.

198 ACZa., Legajo 10 bis, $n^{\circ} 2$ (TBZa.), f. 88 r.

200 ACZa., Legajo 10 bis, no 2 (TBZa.), ff. 88v-92r

J. L. Martin Rodriguez: "Campesinos...", p. 12.

${ }^{201}$ ACZa., Legajo 10 bis, $n^{\circ} 2$ (TBZa.), ff. 88v-92r. 
complirdes que uos prinde e que uos afinque ata que 10 comprades assi como nos mandamos» 202.

El pleito concluye en 1261 con la aceptación por el concejo de la sentencia, que devuelve la villa al obispo, a quien le compensa por los daños sufridos ${ }^{203}$.

Los daños son cuantificados en 400 maravedís por las casas destruidas, en 66 fanegas y media de centeno, 3 fanegas y 5 ochavas de cebada, 5 fanegas y 2 ochavas de mijo, 18 terrazas de vino, 2 cubas, 65 árboles y daños menores por 14 maravedís y cuarto; teniendo que pagar el concejo el doble del importe de las casas, dos árboles por cada uno destruido - de acuerdo con lo mandado por el Fuero de Zamora-, y el triplo del resto de los daños.

Tras ello, don Suero, como señala en su "Apología", emprendería una fuerte tarea restauradora en el lugar ${ }^{205}$ : “ltem, post ruinam domorum de Fremoselle, factam per concilium de Çamora, feci domos per optimas et nemis sumptuosas. Item, feci ibi castrum de novo. Item, emi et feci vineas et domos et dolia cum optimis apotecis".

Sin embargo, pocos años más tarde don Suero se vería desposeído de la jurisdicción sobre la villa por Sancho IV, como consecuencia de su actitud en la guerra civil contra Alfonso $X^{206}$.

La llegada a la diócesis zamorana de Pedro II hizo que el monarca, volviera a entregar a éste "el castiello de Fermoselle et la uila con todos los derechos" a condición de que hicieran "dél siempre guerra e paz" al rey ${ }^{207}$.

Como ha señalado Marciano Sánchez, Pedro II tomó posesión del castillo con un bello ceremonial, el 24 de mayo de 1292, a través de Juan Fernández, escudero de Pay Gómez ${ }^{208}$, quien a su vez lo había recibido de la iglesia de Zamora.

\footnotetext{
202 ACZa., Legajo 10 bis, n² (TBZa.), f. 90v.

M. SÁNCHEZ Rodríguez: Fueros y posturas..., p. 74.

${ }^{203}$ ACZa., Legajo 10 bis, $n^{\circ} 2$ (TBZa.), ff. 88v-92r.; y Legajo 15, $n^{0} 4$.

204 Ibidem.

J. L. Martín Rodriguez: "Campesinos...", p. 24, nota 11.

${ }_{205}$ ACZa., Legajo 10 bis, $n^{9} 2$ (TBZa.), f. 162r.

206 ACZa., Legajo 10 bis, $n^{2} 2$ (TBZa.), f. 95r.

"...lo perdió el obispo don Suero per cosas que fizo".

20. ACZa., Legajo 10 bis, no 2 (TBZa.), f. 95r.

M. SÁNCHEZ RODRIGUEZ: Fueros y posturas..., p. 72.

${ }_{208}$ M. Sánchez Rodriguez: Fueros y posturas..., p. 72.
} 
Un año más tarde el rey volvería a confirmar esta donación ${ }^{209}$.

Pero Pedro II ya no recibe los 12 postores, pues el concejo zamorano influyó, sin duda, en Sancho IV para que les restituyera dicho privilegio.

Por ello no debe extrañarnos que en la confirmación del fuero fermosellano que realiza Sancho IV, se siga incluyendo el acuerdo dicho entre Zamora y Fermoselle, lo mismo que en los años siguientes confirmarían Fernando IV, Alfonso XI y Pedro I ${ }^{210}$.

Un conflicto de gran interés es el que gira sobre la jurisdicción de Aldea del Palo, pues en el se ven enfrentados directamente el concejo zamorano y la iglesia, a través del monasterio de San Miguel del Burgo, y, de forma indirecta, el concejo toresano. Al mismo tiempo va a tener repercusiones sobre la población vecina de Argujillo.

Aldea del Palo — población actualmente denominada San Miguel de la Ribera - era un lugar en la zona de contacto de las tierras de Zamora y Toro, en el límite con La Guareña, razón por la que fue objeto de múltiples conflictos entre ambos concejos.

A ello se unía el compartir jurisdicción sobre el lugar, o estar superpuestas, el concejo zamorano con el monasterio benito de San Miguel del Burgo.

El conflicto parece iniciarse a mediados del siglo XIV, aunque tuvo su punto álgido a fines de dicha centuria, durante el tiempo en que fue prior de San Miguel del Burgo fray Fernán Gómez ${ }^{211}$.

El propio fray Fernán Gómez señala, en 1399, que "andovieron en pley[tos e] contiendas con el conçejo de la dicha çibdad de Çamora e con sus p[roculradores en la corte de nuestro señor el rey avia çerca de treynta

\footnotetext{
ACZa., Legajo 10 bis, $n^{\circ} 2$ (TBZa.), f. 95r-v.

"Alfonso Rodriguez porteiro del rey entregou el castiello e la vila de fermoselle a lohán Fernández, escudero de don Pay Gómez por nomre del obispo e del cabildo de Camora, que lo dieron a don Pay Gómez por en sos dias que lo touiesse de los, et despoys de sos dias que lo entregasse a la eglesia de Çamora e a outro nenguno. Et lohán Fernández sobredicho reçibió el cas. tiello; e después que fu entrego del, chamou se estaua y alguno por el obispo ou por el cabildo de Çamora. Et respondió lohán Diaz, notario de la eglesia de Çamora. Dixo que fería testimonio de lo que el dixiesse. Et lohán Fernández dixo de çima del castiello que aquel castiello que era entrego dél e que lo tenia por don Pay Gómez por nomre del obispo e del cabildo de Camora e non de outro nenguno; et se don Pay Gómez morisse en este comedio que él daría el castiello e la uila al obispo e al cabildo de Çamora cuio era e non a outro nenguno, nen a rey nen a reyna. Et alançou tres piedras fuera del castiello en reconosçencia destas palauras que furon dichas tres uezes".

209 ACZa., Legajo 10 bis, $n^{\circ} 2$ (TBZa.), ff. 95v-96v.

${ }^{210}$ AHPZa.: Sección Municipal: Zamora, Legajo XVI, nº 3.

211 AHPZa.: Sección Municipal: Zamora. Libro 267 (Tumbo Municipal), ff. 1r-6v.
} 
a[ños] sobre el lugar e jurisdiçión ceuil e criminal e mero mixto [inpe]rio de la Aldea del Palo que es en término de la dicha çibdad, [dezien]do los dichos priores que eran del dicho monesterio e que devian [ser] restituidos " 212.

El concejo, por su parte, señalaba "que avia bien sesenta [años] que 10 tenía el dicho conçejo de posesión e lo poseya» ${ }^{213}$.

Para poner fin al conflicto, que estaba suponiendo grandes gastos a ambas partes, deciden poner el caso en manos de dos jueces, nombrados de común acuerdo, que dictasen el correspondiente laudo. Los elegidos fueron don Juan, obispo de Zamora, y el regidor Ordón Ruiz de Villaquirán, el primero por parte del monasterio y el segundo por el concejo.

La sentencia, hecha pública, previsiblemente, a fines de septiembre de 1399 , señalaba que Aldea del Palo quedaría sujeta a la jurisdicción concejil zamorana, recibiendo el monasterio en comperisación a la misma unas considerables ventajas.

Así, se señalaba que "el dicho conçejo que dé treynta e un mill maravedis de moneda vieja para que se conpren dellos posesyones que rrienden para el dicho monesterio e priores que fueren dél en cada años dos mill maravedis en saluo; e si algunos maravedís sobraren de los dichos treynta e vn mill maravedís que se die[ran] al dicho prior para rreparamiento del dicho monesterio [e d]e las heredades dél, e que aya más el dicho monesterio e el prior que fuer dél diez escusados que moren en el corral del [dicho] monesterio que no sean de los vezinos que agora moren en [Çam]ora e su tierra; e aya más un escusado en el dicho lugar del Al[dea] del Palo e que estos no paguen en los pechos e rreparti[mie]ntos conçejales; e que aya más el dicho monasterio e prior [que] dél fuer todos los diezmos del dicho lugar e la metad [de] la martiniega e sus casas e heredades que el dicho [mon]esterio y ha. E por estas dichas cosas que Çamora ha [...]ar e fazer que el dicho lugar del Aldea del Palo e la [juris]diçión çevil e criminal e mero mixto inperio del dicho [lug]ar que finque e sea todo libre e quito de la dicha çibdad de [Çam]ora e del conçejo della e la aya para sy, segund que todo [...] mejor e más cunplidamente se contenia en la dicha [...] que el dicho señor obispo e el dicho Hordón Ruys die[ron] entre las dichas partes e estava escripto por mi el dicho [Sancho] Romero notario e por Françisco Martínez notario a[postolical]" ${ }^{214}$.

\footnotetext{
212 Ibidem.

213 Ibidem.

${ }^{214}$ Ibidem.

El documento ha sufrido grandes daños, por lo que son numerosas las lagunas en el texto.
} 
A fin de que dicho acuerdo fuese más estable, se solicitó del rey, del papa y del obispo que confirmasen dicha sentencia ${ }^{215}$.

La confirmación regia se produjo en marzo de 1400, sin que haya constancia de la pontificia.

Sin embargo la jurisdicción sobre Aldea del Palo siguió suponiendo graves problemas años después, pues al poco tiempo el prior de dicho monasterio, tras haber invertido en diversas propiedades 27.350 maravedís de los 31.000 concedidos por la ciudad, señala que no va a poder conseguir la renta anual prevista de 2.000 maravedís, y reclama que se realice un nuevo convenio.

En diciembre de 1423, el nuevo prior del monasterio de San Benito, fray Pero Ferrández solicita la anulación de una parte del anterior acuerdo ${ }^{216}$.

Señala que los 27.350 maravedís han sido invertidos - salvo unas pequeñas cantidades en la reparación del monasterio- en la adquisición de tres casas y bodegas, con un total de 24 cubas y 2 tinajas, situadas en la cuesta de El Piñedo, en Balborraz y en El Valle en la calle en que vivía Antón Martín Garrido. Los 3.650 mrs. restantes estaban en poder de lohán Martín Sobrino y lohán Alfonso de Algodre, designados por ambas partes como depositarios. Pero que con lo comprado y el dinero restante es imposible obtener una renta de 2.000 maravedis, y por lo tanto denuncia el convenio.

Ante ello, ambas partes - concejo y monasterio- acuerdan que ${ }^{217}$ :

- El monasterio devolverá al concejo las tres propiedades adquiridas con los $27.350 \mathrm{mrs}$.

- lohán Martín Sobrino y lohán Alfonso de Algodre reintegrarían al concejo los $3.650 \mathrm{mrs}$. restantes.

- El concejo se comprometía a dar al monasterio $2.000 \mathrm{mrs}$. anuales, impuestos sobre la renta de los cuchares del pan, pagaderos el dia de Nochebuena de cada año a partir de 1424.

- El resto de lo acordado en 1329 se mantenía.

215 Ibidem.

"E dixe]ron que pedian por merçed a nuestro señor el Padre Santo e [a nuestro] señor el rey e a nuestro señor el obispo desta cibdad e a [cada] vno dellos que les plega dello, e den a ello su liçencia [e alutoridad e decreto para que valga e sea firme palra] syenpre jamás".

216 AHPZa.: Sección Municipal: Zamora. Legajo LXXV, no 1 <provisional>.

217 Ibidem. 
A fin de garantizarse esa renta anual a valores constantes, se señala que esa cuantía de $2.000 \mathrm{mrs}$. sea de la moneda vieja, teniéndose que actualizar cada vez que hubiera cambio en el porcentaje exacto de la desviación inflacionista; sino fuera suficiente la renta de los cuchares o no se cogiere, se sacaría el dinero de otra renta; si tampoco fuera posible, se repartiría esa cantidad entre los vecinos de la ciudad y su tierra.

Parecía resolverse así el problema, sin embargo, periódicamente, siguieron surgiendo nuevas dificultades en torno a la jurisdicción del lugar.

Por los mismos años en que comenzaron los problemas de Aldea del Palo - es decir, sobre los primeros años del segundo tercio del siglo XIV-, Alfonso IX iba a otorgar un privilegio en virtud del cual confirmaba que Argujillo y sus habitantes eran de realengo ${ }^{218}$.

Aunque pueda parecer casual, hay varios hechos interesantes por los que se relacionan dichos lugares. Por un lado, la proximidad geográfica de ambos, que son limítrofes. Por otro, los problemas que conjuntamente ocasionaron con Toro, y así el 31 de agosto de 1459 se hubo de llegar a un convenio entre la ciudad de Zamora con aquella, como en su momento veremos, sobre la división de términos entre Aldea del Palo y Argujillo ${ }^{219}$.

Un conflicto sangriento, ejemplo de los que surgen contra las jurisdicciones monásticas, es el que va a enfrentar sobre 1360 a los vecinos de Fuentelcarnero contra el monasterio de Valparaíso.

En 1360, y como consecuencia de las sanciones impuestas por el monasterio a los vecinos de ese lugar - dependiente de la ciudad de Zamora-que sin permiso habian arrancado en el monte de El Cubeto escobas, hiniestas, tomillos, jaras y otros arbustos, se rebelaron contra el convento armados de hoces, palos y objetos aguzados y contundentes. El resultado fue la muerte de un fraile de avanzada edad acribillado de siete lanzadas y el intento de degollamiento con hoces del prior ${ }^{220}$.

Restablecida la calma, se inició la persecución de los culpables por el monasterio y un proceso que concluyó con un compromiso entre ambas partes cerca de 130 años después, en 1492. Sin embargo, las graves penas impuestas supusieron el abandono masivo de la tierra de Fuentelcanero.

218 AHPZa.: Sección Municipal: Zamora. Libro 267 (Tumbo Municipal), ff. 8v-9v.; y Legajo LXXXII <provisional>

${ }_{219}$ AHPZa.: Sección Municipal: Zamora. Legajo XVII, $n^{\circ} 7$

220 AHDZa., Libros manuscritos $n \cong 82$ (Tumbo de Valparaíso), f. 332r.

AHPZa:: Desamortización, leg. 206, $n^{2} 3$. 


\section{b) Conflictos entre concejos}

La existencia de dos núcleos concejiles de gran importancia, tanto económica como estratégica, en la línea del Duero a tan sólo 30 kilómetros de distancia, hizo que desde el siglo XII fueran claros los intentos de que sus zonas de confluencia estuvieran perfectamente delimitadas.

Así, no debe extrañarnos que, cuando, en 1139, Alfonso VII dona al obispo la villa de Fresno de la Ribera, señale que está situada entre Toro y Zamora, junto al Duero, rodeada por las zamoranas San Pelayo y Coreses y por la toresana Maria Alba ${ }^{221}$. Y que, veinticinco años después, al autorizarse la construcción de unas aceñas en dicho lugar, se vuelva a recalcar esa situación entre los territorios de dichos grandes concejos ${ }^{222}$.

Lugar que se diferencia perfectamente en la documentación de Fresno el Viejo - en la actual provincia de Valladolid-, al que siempre se señala su pertenencia al término de Toro ${ }^{223}$.

Los primeros problemas que conocemos por la delimitación de términos entre Zamora y Toro se centran en los primeros años del siglo XIII en la zona de Venialbo.

Venialbo había sido donado al zamorano monasterio de Santo Tomás por Alfonso VII, en $1124^{224}$, siendo confirmado este hecho dos años después ${ }^{225}$. Posteriormente, en 1135 , el propio emperador cedería dicho lugar a la iglesia de Zamora - como parte de las propiedades del monasterio de Santo Tomás- para la construcción de la catedral ${ }^{226}$.

El concejo de Toro, en su afán de consolidar sus límites en las zonas de La Guareña y Tierra del Vino, en la que no existen accidentes geográficos claros, pronto hostigará a los habitantes de Venialbo, como ha estudiado Marciano Sánchez ${ }^{227}$; y lo mismo hará el concejo zamorano. Por

2a) ACZa., Legajo 8, nº 6 .

2a2 ACZa., Legajo 13, nº 27.

223 Asi en el reconocimiento, realizado en 1197, por Martín I de una deuda a Mayor Farte y sus hijos por la compra de unas aceñas, de unos huertos y de unas viñas se recalca "quas habebatis in Freisno de termino Tauri...".

ACZa., Legajo 13, $n^{\circ} 40$.

Muchas son las referencias de este tipo que podriamos citar, aunque no lo consideramos necesario.

${ }_{224}$ ACZa., Legajo 10 bis, $n^{\circ} 1$ (TNZa.), f. XIX r-v.

225 Ibidem., p. 84.

226 Ibidem., p. 26.

ACZa.: Legajo 8, n 5.

${ }_{227}$ M. Sánchez Rodríguez: Fueros y posturas..., pp. 8-10. 
ese motivo, a principios del siglo XIII, tras numerosos conflictos, y ante la petición de justicia del obispo Martín II, se llega a un acuerdo sobre términos ante la curia regia entre Zamora, Toro y Venialbo ${ }^{228}$. Acuerdo que, pronto, se incumplió por Toro, por lo que se hizo necesaria una nueva actuación de Alfonso IX ${ }^{229}$.

En los años siguientes, Zamora y Toro se pondrán de acuerdo en una nueva delimitación de términos en el lugar, que va a suponer paralelamente una pérdida de los derechos del obispo en Venialbo, que pasaba, posiblemente, a la jurisdicción de Toro. Por ese motivo, Pedro I denuncia el hecho ante el rey, que obliga a Toro a volver a la situación anterior ${ }^{230}$.

El problema, ya sin la intervención de Zamora, y tras varios avatares, finalizará en $1266^{231}$.

Un nuevo contencioso se suscita sobre 1376, en gran medida por el cambiante cauce del arroyo Talanda, lo que obliga a poner en manos de la reina doña Juana la resolución del conflicto, quien a su vez determinó que fueran el arcediano de Toro, Juan Sánchez, y el corregidor de Zamora, Ruy González de Salamanca, quienes deslindasen los términos. Con tal motivo, se produce la delimitación entre Sanzoles y el río Duero ${ }^{232}$.

El período de máxima conflictividad es el de la segunda mitad del siglo $X V$ y primeros años del s. XVI.

En 1459, como ya señalamos, se produce un nuevo conflicto entre Zamora y Toro, en este caso por la delimitación de términos entre Aldea del Palo y Argujillo, en el que también se ve afectado de nuevo Venialbo.

Ante los numerosos incidentes que se venian produciendo en esa zona, por haberse movido los antiguos mojones, fueron comisionados los regidores García Docampo, por parte de Zamora, y Pedro Puertocarrero, por la de Toro, quienes procedieron a una nueva demarcación de términos, en la que queda patente la total pertenencia de Aldea del Palo y Argujillo a la tierra de Zamora, a la vez que se confirman los límites de

${ }^{228}$ ACZa.: Legajo 15, no 15; y Legajo 10 bis, $n^{\circ} 2$ (TBZa.), f. $64 r-v$.

229 Ibidem.

230 Ibidem.

"Mando vobis firmiter quod no contrarietis hominibus de Venialvo laborare et curtare in suo termino quomodo laboraverunt et curtaverunt ab antiquo, quia no volo nec teneo pro directo quod pro divisione termini inter vos et illos de Zamora facta episcopus perdat suam hereditatem in termino vestro".

231 ACZa.: Legajo 15, n 16, 17 y 18; y Legajo 10 bis, $n^{\circ} 2$ (TBZa.), f. 224.

232 AHPZa.: Sección Municipal: Zamora, Legajo XI, $\mathrm{n}^{\circ} 2$.

M. F. Ladero Quesada: Opus cit., pp. 9 y 27-28, nota 103. 
Venialbo, situándose en primer mojón en la confluencia de las Tierras de Toro, Zamora y el citado Venialbo ${ }^{233}$.

En 1487, parece volverse a recrudecer el contencioso de 1376. Ese año se va a resolver el problema de los linderos en Tierra del Vino, fundamentalemnte en los términos entre Santa María del Valle y Sanzoles ${ }^{234}$.

Siete años más tarde se intentará poner fin al resto del espacio limitrofe hasta el Duero, zona donde habían vuelto a surgir problemas ${ }^{235}$.

Así pues, en tan sólo 35 años -entre 1459 y 1494-Zamora y Toro revisan y hacen convenios sobre limites en toda su «raya» al sur del Duero.

Desde ese momento el territorio objeto de controversias será el situado al norte de dicho río, que comienza a ser objeto de conflictos desde 1495 , aunque su desarrollo mayor se producirá entre 1501 y 1502, en que se revisan los linderos con la Tierra del Pan ${ }^{236}$.

El último de esos problemas del siglo XV es el que, como ya hemos señalado, se produce en 1495, por la denuncia de Zamora ante los Reyes Católicos a consecuencia de los problemas surgidos en Montelarreina y en el arroyo de $\mathrm{Val}$ de Zulema, pues los toresanos habían realizado numerosos apresamientos, retenciones de ganado e impuesto muchas multas ${ }^{237}$.

Junto a estos conflictos hay otros muy especiales, que concluyen en sendos hermanamientos entre ambas ciudades.

Las tensiones entre monarquía y nobleza en los años finales del reinado de Enrique IV tienen una de sus plasmaciones en Zamora en los graves quebrantos que van a ocasionar en las tierras de Toro y Zamora Juan de Ulloa -apodado el "Tresquilado" y "Ulloa el Malo»- y Pedro de Avendaño, alcaide de Castronuño, quienes cometieron toda clase de desmanes, hasta que los zamoranos les hicieron frente en Val de la Gallina, en las proximidades de Coreses, donde cayeron derrotados ${ }^{238}$.

\footnotetext{
233 AHPZa: Sección Municipal: Zamora, Legajo XVII, ñ 7.

M. F. LaDeRo Quesada: Opus cit, pp. 19 y 28, nota 104.

234 AGS.: Consejo de Cámara, Pueblos: Legajo 23, $n^{\circ} 4$.

M. F. LaDero Quesada: Opus cit., p. 19.

${ }^{235}$ AHPZa: Sección Municipal: Zamora, Legajo XVII, nº 15.

M. F. Ladero Quesada: Opus cit, p. 19.

V.AA.: Historia de Zamora. La Opinión, Zamora, 1991. Tomo II, pp. 276-277.

236 AHPZa.: Sección Municipal: Zamora, Legajo XVII, $n^{\circ} 17$; y Libros de Actas $n^{\circ} 1$ y 1 bis.

237 AHPZa.: Sección Municipal: Zamora, Libro 267 (Tumbo Municipal), ff. 83v-84r. AGS: RGS: 15 de julio de 1495, f. 256.

${ }_{238}$ VV.AA.: Historia de Zamora. La Opinión, Zamora, 1991. Tomo I, pp. 248.

C. Fernández Duro: Memorias históricas de la ciudad de Zamora, su provincia y obispado. Rivadeneyra, Madrid, 1882, Tomo II, pp. 44-47.
} 
Este hecho, que causó una gran inestabilidad en las tierras de Zamora y Toro, va a dar lugar a la realización de "una escritura de capitulación de hermandad, amistad y confederación" entre ambas ciudades en noviembre de 1474, que, además de plantear una defensa común, supone el reconocimiento de todos los límites territoriales y la afirmación de no ir contra sus jurisdicciones. Pero además, significa la firma del aclierdo también con Pedro de Mendaña, nuevo alcaide de Castronuño ${ }^{239}$.

Un nuevo tratado de amistad se produce en 1492, en el que se plantea una misma actitud en los pleitos que puedan tener ambas comunidades con la iglesia en relación a las tasas a pagar por ésta para mantenimiento y construcción de puentes, muralias o calles; pero también se plantea el uso del término de San Martín de las Olivas cuya jurisdicción compartían ambos concejos ${ }^{240}$.

\section{c) Conflictos entre concejo y señoríos laicos}

Un curioso enfrentamiento de tipo jurisdiccional se produce en el último año del siglo XV entre Avedillo y Zamora.

Avedillo era en esos momentos un lugar perteneciente al doctor Rodrigo Maldonado de Talavera.

La causa del enfrentamiento es la instalación del patíbulo $u$ horca de Avedillo en término de Zamora.

Los problemas comienzan a surgir a principios del año 1500.

Por esas fechas, el doctor Rodrigo Maldonado de Talavera retiró la horca de Avedillo del emplazamiento donde siempre habia estado "cabe las casas del dicho lugar», situándola en el pago de Bufino, "en el término o juridiçión mero e misto ymperio, alto e bajo, çevil e cryminal"s de Zamora ${ }^{241}$.

Enterado el concejo zamorano, procedió inmediatamente a su destrucción. Pero fue vuelta a colocar por el doctor Maldonado, quien además tuvo la osadía de que "syn previllejo algunno ni título ni posesión ynmemorial ni otro derecho alguno nuevamente ha querido e quiere llevar portazgo o ynpusyçión nueva en el dicho lugar de Avedillo a los que

\footnotetext{
239 AHPZa.: Sección Municipal: Zamora, Legajo LXXV <provisional>.

${ }_{240}$ VV.AA.: Historia de Zamora. La Opinión, Zamora, 1991. Tomo II, pp. 277.

AHPZa.: Sección Municipal: Zamora, Leg. A-5-2, no $39<$ provisional>.

Estaba situado en el actual término municipal de Villalazán.

${ }^{241}$ AHPZa: Sección Municipal: Zamora. Legajo C-1 <provisional>.
} 
por él pasan por ser derechos que non pueden llevar ni acostunbrado llevar" 242 .

A fin de que el enfrentamiento no se prolongase en un largo juicio, ambas partes decidieron nombrar dos letrados que analizaran el problema en procedimiento abreviado y dictaran el correspondiente laudo en el plazo de 30 días, que ambas partes aceptaban de antemano. Siendo elegidos el bachiller Pedro de Sotelo y el doctor Tomás; quienes podrían señalar una tercera persona si no llegaran a acuerdo ${ }^{243}$.

Desconocemos la sentencia dictada, pero no dudamos que hubo de ser favorable a la ciudad. Sin embargo, el 23 de septiembre, vuelve a surgir, en parte, el problema. Visitando el corregidor y varios regidores los términos de la ciudad y de su tierra "fallaron puesta una horca en tierra e jurediçión de la dicha çibdad, la qual está çerca del lugar de Avedillo, lugar del señor dotor de Talavera, la qual dicha horca avian puesto del dicho lugar de Avedil'o", que inmediatamente mandaron derribar y hacer pedazos ${ }^{244}$.

A continuación se dirigieron al lugar de Avedillo, reuniendo en el atrio de la iglesia a la mayor parte de los vecinos, a los cuales amenazó el corregidor -en nombre de los reyes-con graves castigos si volvian a poner el patibulo en término de Zamora, mandándoles que lo situaran donde solían antes estar ${ }^{245}$.

El siguiente paso fue comprobar si en dicho lugar estaba situada, y comprobaron que no. Por último se dirigieron al Cerro de la Horca, donde fue colocada y en el que, varios testigos de Corrales, dijeron que alli la habian visto desde hacía, al menos cuarenta años, y que alli habían sido ajusticiados Andrés Manzano y Pedro Guzmán ${ }^{246}$.

iła AHPZa.: Sección Municipal: Zamora. Legajo C.2 <provisional>.

:45 loidem.

215 lbidem. 